\title{
ENSO-correlated fluctuations in ocean bottom pressure and wind-stress curl in the North Pacific
}

\author{
D. P. Chambers \\ College of Marine Science, University of South Florida, St. Petersburg, FL 33701, USA \\ Received: 23 June 2011 - Published in Ocean Sci. Discuss.: 8 July 2011 \\ Revised: 11 October 2011 - Accepted: 13 October 2011 - Published: 25 October 2011
}

\begin{abstract}
We examine the output of an ocean model forced by ECMWF winds to study the theoretical relationship between wind-induced changes in ocean bottom pressure in the North Pacific between 1992 until 2010 and ENSO. Our analysis indicates that while there are significant fluctuations correlated with some El Niño and La Niña events, the correlation is still relatively low. Moreover, the ENSOcorrelated variability explains only $50 \%$ of the non-seasonal, low-frequency variance. There are significant residual fluctuations in both wind-stress curl and ocean bottom pressure in the region with periods of 4-years and longer. One such fluctuation began in late 2002 and has been observed by the Gravity Recovery and Climate Experiment (GRACE). Even after accounting for possible ENSO-correlated variations, there is a significant trend in ocean bottom pressure in the region, equivalent to $0.7 \pm 0.3 \mathrm{~cm} \mathrm{yr}^{-1}$ of sea level from January 2003 until December 2008, which is confirmed with steric-corrected altimetry. Although this low-frequency fluctuation does not appear in the ocean model, we show that ECMWF winds have a significantly reduced trend that is inconsistent with satellite observations over the same time period, and so it appears that the difference is due to a forcing error in the model and not an intrinsic error.
\end{abstract}

\section{Introduction}

The area between $35^{\circ} \mathrm{N}$ to $50^{\circ} \mathrm{N}$ and $150^{\circ} \mathrm{E}$ to $180^{\circ} \mathrm{E}$ in the North Pacific has some of the highest variance of longwavelength ocean bottom pressure (OBP) in the world's oceans. It is caused by mass transport into and out of the region due to changes in the wind-stress curl (WSC) over the sub-polar and sub-tropical gyres (e.g., Ponte, 1999). Initial

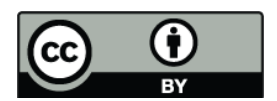

Correspondence to: D. P. Chambers (dchambers@marine.usf.edu) work focused on quantifying the seasonal variation (e.g., Ponte, 1999; Bingham and Hughes, 2005), but more recent studies have also documented significant low-frequency fluctuations (Song and Zlotnicki, 2008; Chambers and Willis, 2008).

The seasonal cycle of the OBP and WSC variations has been well documented elsewhere (Ponte et al., 1999; Bingham and Hughes, 2005) and is summarized here. Wind-stress curl is generally positive north of $40^{\circ} \mathrm{N}$ and negative to the south, although seasonal variations will cause the magnitude to strengthen or weaken (Fig. 1). The gradient is generally the strongest in November to February, and weakest in June to August. Because the integrated meridional mass transport is directly proportional to wind-stress curl, anomalous WSC causes changes in the mass transport. In December, the anomalous transport is poleward and equatorward from $40^{\circ} \mathrm{N}$, causing a transport of mass away from $35 \mathrm{~N}-45^{\circ} \mathrm{N}$; this leads to a drop in OBP in the subpolar gyre and an increase in the subtropical gyre (Fig. 1). In July, the gradient across $40^{\circ} \mathrm{N}$ is weaker, allowing mass to flow back into the region, resulting in an increase in OBP in the area and a drop to the south. The OBP variability is intensified in the western portion of the sub-polar gyre due to trapped modes caused by changes in bathymetry and conservation of potential vorticity (Ponte, 1999). The anti-correlation between OBP and WSC in the subpolar gyre (north of $40^{\circ} \mathrm{N}$ ) holds for high frequency, seasonal, and low-frequency variations (Ponte, 1999; Song and Zlotnicki, 2008).

There have been numerous studies describing interannual variations in the upper ocean temperature, salinity, and sea level in the North Pacific (e.g., Qiu and Joyce, 1992; Miller et al., 1998; Fu and Qiu, 2002; Qiu, 2002; 2003), with most of the variations linked to wind-forcing and the Rossby wave responses that are confined to the upper ocean $(\mathrm{Fu}$ and Qiu, 2002). A substantial portion of the internnaul variability has been tied to the Pacific Decadal Oscillation (PDO) (Qiu, 2003). Qiu (2002), based on an analysis of

Published by Copernicus Publications on behalf of the European Geosciences Union. 


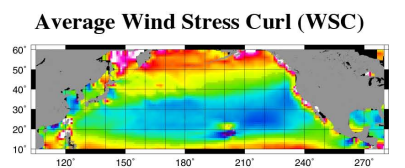

December Anomalous WSC
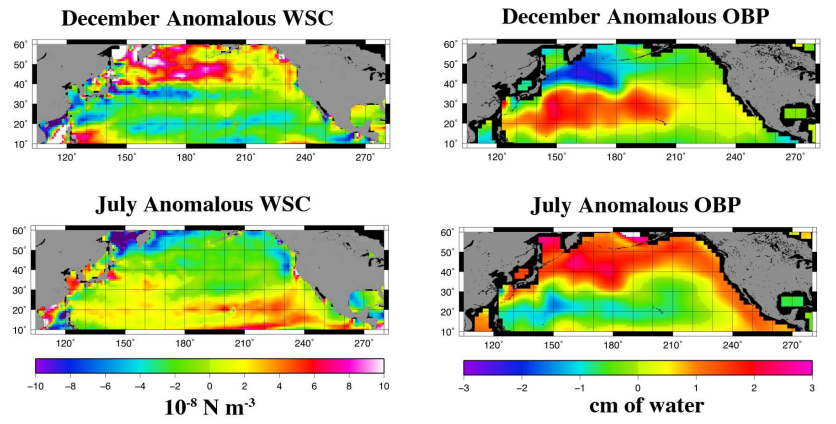

Fig. 1. Maps of WSC (left) and OBP (right) anomalies relative to a long-term mean (1992-2008) showing the average December anomaly (middle) and July anomaly (bottom). These represent the extreme anomalies of the seasonal cycle. The monthly averages were computed from the satellite observations and OMCT for all years from 1992 until 2008. The mean WSC is shown at the top left. The mean OBP will just reflect the mean water height of the ocean, and so is not shown.

time-dependent Sverdrup balance along with an assumption of constant bathymetry across the North Pacific, concluded that there were no low-frequency fluctuations of mass in the area related to wind forcing. However, changes in topography over the region are quite substantial, and have been shown to cause trapped modes (Ponte, 1999). More recently, Song and Zlotnicki (2008) used a wind-forced model with realistic bathymetry and demonstrated significant interannual variations in OBP related to WSC in the region. They also concluded that there was a small, barely significant correlation between both WSC and OBP with an El Niño/Southern Oscillation (ENSO) climate index at a lag of 0 to 2 months. They discussed in some detail the WSC and OBP variations associated with the large 1982/1983 and 1997/1998 El Niño events. However, the correlation between the non-seasonal, low-pass filtered WSC and OBP in their study was much higher in the same region, indicating significant low-frequency variations that were not correlated to ENSO. Chambers and Willis (2008) demonstrated a general increase in OBP in the North Pacific sub-polar gyre from early-2003 until mid-2007, using observations from the Gravity Recovery and Climate Experiment (GRACE) as well as steric-corrected altimetry. Although the time-span was too short to conclusively link all the variability with ENSOcorrelated variation Song and Zlotnicki (2008) modeled, they concluded that the change was at least consistent with the theory.

In this study, we will re-examine the ENSO-correlated variations in both OBP and WSC in the North Pacific, and quantify how much of the non-seasonal, low-frequency variability is correlated with ENSO variations in the tropical Pacific. To do this, we will utilize a record of wind-stress data from satellite scatterometers and radiometers from 1992 to 2009, OBP output from a baroclinic model also from 1992 to 2009, as well as OBP variations estimated from GRACE from 2003 until the end of 2010. As part of this study, we will determine whether the long-period fluctuation observed by Chambers and Willis (2008) is related mainly to El Niño/La Niña events, or whether it reflects a distinctly different low-frequency fluctuation. Sect. 2 will describe the data and methods, Sect. 3 will quantify the ENSO-correlated fluctuations in WSC and OBP, and Sect. 4 will summarize the results and discuss residual, low-frequency variations unrelated to ENSO.

\section{Data processing and methods}

To examine the variable WSC in the region, we use monthly gridded vector winds from a combination of various satellite sources distributed by the Cross-Calibrated Multi-Platform (CCMP) Ocean Surface Wind Components Project at the Jet Propulsion Physical Oceanography Distributed Active Archive Center (http://podaac.jpl.nasa.gov/ DATA_CATALOG/ccmpinfo.html). We use the Level 3.5a products that have been gridded into monthly files based on an optimal interpolation of various satellite scatterometer and radiometer data sets, with modifications to accommodate special attributes of the satellite surface wind data as well as some additional tuning of the data including quality checking and filter weights (Atlas et al., 1996). Wind-stress is computed from the wind vectors using the bulk formula with a value of $1.2 \mathrm{~kg} \mathrm{~m}^{-3}$ for the density of air and the algorithm for the coefficient of drag $\left(C_{\mathrm{D}}\right)$ from Large and Pond (1982). The curl of the wind-stress is computed from the $1^{\circ}$ grids via center-differences.

For the modeled OBP, we use output from the Ocean Model for Circulation and Tides (OMCT) forced by ECMWF winds and pressure at $6 \mathrm{~h}$ intervals, provided by GFZ Potsdam (Thomas, 2002; Flechtner, 2007). OMCT is run at a step size of $30 \mathrm{~min}$, with a constant horizontal resolution of $1.875^{\circ}$ in longitude and latitude, and 13 vertical layers. The output from this model has been averaged over monthly intervals to be consistent with the WSC data. OBP is converted to equivalent water thickness (e.g., Ponte, 1999) using a mean density of seawater of $1027 \mathrm{~kg} \mathrm{~m}^{-3}$ and the hydrostatic equation.

GRACE observations are from the Center for Space Research (CSR) at the University of Texas, Austin that have been processed as described in Chambers (2006) and are publicly available from the GRACE Tellus web-site (http: //gracetellus.jpl.nasa.gov). These data have additionally been projected onto Empirical Orthogonal Functions (EOF) of ocean bottom pressure from OMCT, and have been 
reconstructed into new grids using the technique described fully in Chambers and Willis (2010). In that study, the EOF Reconstruction (EOFR) technique was shown to remove a significant amount of noise from the original GRACE maps, via a global residual analysis with steric-corrected altimetry data. The new EOFR grids agreed significantly better with steric-corrected altimetry data than either the original grids or model output. In the North Pacific, the variance of the residuals (altimeter - Argo - GRACE) dropped from $8.1 \mathrm{~cm}^{2}$ for the original gridded data to $5.0 \mathrm{~cm}^{2}$ for the GRACE EOFR data, compared to $6.0 \mathrm{~cm}^{2}$ when compared to the model used for the EOFs. These EOFR filtered data are also now available on the GRACE Tellus web-site.

Both the OMCT and GRACE data have a variable global mean OBP from a combination of mean atmospheric pressure variations and ocean mass variations (e.g., Chambers and Willis, 2010). Since this study is focused on internal mass redistributions and not global mass variations, we have removed the monthly global mean from both the GRACE and OMCT data. Additionally, we have low-pass filtered the data to remove seasonal and high-frequency variations in order to isolate low-frequency variations. This was done by first fitting and then removing seasonal-period sinusoids using least-squares estimation at each grid point, then further smoothing the residuals with a 90-day Gaussian smoother. This was done for all data-sets.

\section{Analysis of ENSO-correlated variations}

The leading EOF of non-seasonal WSC from the satellite data and OBP from OMCT over the North Pacific is shown in Fig. 2. The spatial mode is similar to the pattern of seasonal variability for WSC, with the largest variations occurring just north and south of $35^{\circ} \mathrm{N}$. For OBP, the variability is largest between $35-50^{\circ} \mathrm{N}$. The correlation of the leading principal component (PC) of WSC and OBP with the Multi-Variate ENSO Index (MEI) (Wolter and Timlin, 1998) is 0.69 and -0.54 respectively, both of which, while significantly different than would be expected from random chance at the $99 \%$ level, are still not high to indicate that the ENSO mode is robust. We chose to use the MEI over other ENSO indices like the Nino3, Nino4, Nino3.4, or Southern Oscillation Index (SOI), as it attempts to use multiple parameters that are related to ENSO (SST, zonal and meridonal winds, and pressure) over a broader area, as opposed to a single parameter in a small region. While the Nino and SOI indices were developed based on available limited older data, the MEI uses more large-scale observations and understanding of ENSO dynamics to create an index, and thus arguably gives better insight to the large-scale ENSO timing rather than the timing in only the eastern Pacific, which may lag or lead the larger pattern. The correlation between the PCs of WSC and OBP is significantly higher $(-0.89)$ than either are with the MEI, which further indicates that not all of the low-frequency
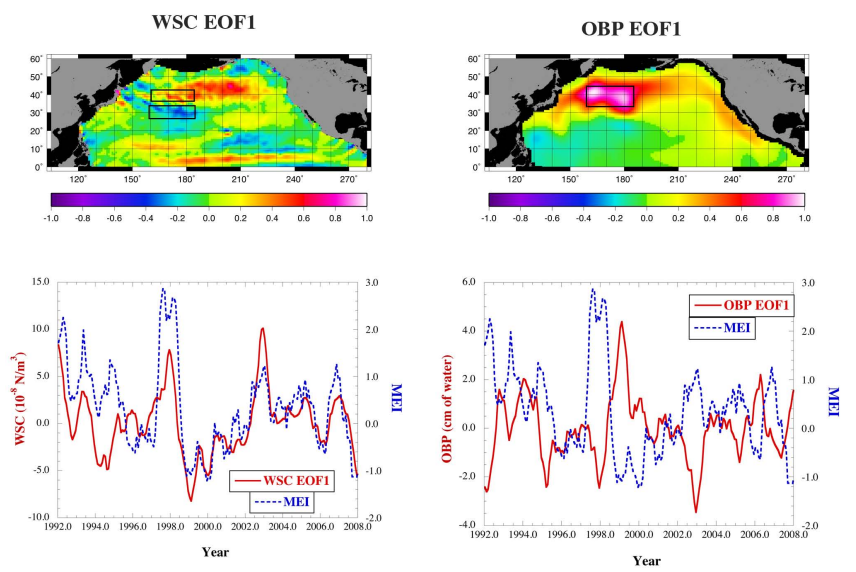

Fig. 2. Leading EOFs (top) and principal components (bottom) of WSC from CCMP (left) and OBP from OMCT (right). The EOFs have been normalized, so that the spatial patterns have a maximum of \pm 1 and the principal components represent the magnitude of variability. Data were low-pass filtered to isolate non-seasonal, lowfrequency variations as described in Sect. 2, and the EOFs were computed using only data north of the equator in the Pacific and excluding coastal regions for OBP. The MEI is also shown for comparison to the principal components. Boxes indicate areas where data are averaged for further comparison. See text for details.

variability is related to ENSO. No other EOF mode has a significant correlation with the MEI, even with lags of up to 1-year.

The pattern and timing of the ENSO-correlated variations of WSC and OBP shown in Fig. 2 is similar to what was described earlier by Song and Zlotnicki (2008). WSC anomalies north of $35^{\circ} \mathrm{N}$ are generally anomalously positive during an El Niño, but negative during a La Niña. The opposite is true for the area south of $35^{\circ} \mathrm{N}$. When the difference of WSC north and south of $35^{\circ} \mathrm{N}$ is large and positive (e.g., during the 1997/1998 El Niño), OBP in the sub-polar gyre is anomalously low. When the WSC difference is large and negative (e.g., during the 1998/1999 La Niña), the OBP in the sub-polar gyre is anomalously high.

The EOF analysis, however, allows for a better quantification of where the variability occurs. For instance, Song and Zlotnicki (2008) used a rather large area to the north and south $\left(40^{\circ} \mathrm{N}-50^{\circ} \mathrm{N}, 150^{\circ} \mathrm{E}\right.$ to $200^{\circ} \mathrm{E} ; 20^{\circ} \mathrm{N}$ to $30^{\circ} \mathrm{N}$, $150^{\circ} \mathrm{E}$ to $200^{\circ} \mathrm{E}$ ) and computed a WSC index ( $\triangle \mathrm{WSC}$ ) as

$\Delta \mathrm{WSC}=<\mathrm{WSC} \_\mathrm{N}>-<\mathrm{WSC} \_\mathrm{S}>$,

where $<$ WSC_N $>$ was the anomalous WSC averaged over $40^{\circ} \mathrm{N}-50^{\circ} \mathrm{N}, 150^{\circ} \mathrm{E}$ to $200^{\circ} \mathrm{E}$ and $<\mathrm{WSC} \_\mathrm{S}>$ was the anomalous WSC averaged over $20^{\circ} \mathrm{N}-30^{\circ} \mathrm{N}, 150^{\circ} \mathrm{E}$ to $200^{\circ}$ E. From Fig. 2, though, it is apparent that the largest ENSO-correlated variability south of $35^{\circ} \mathrm{N}$ is actually centered at $30^{\circ} \mathrm{N}$ and does not extend farther south than $25^{\circ} \mathrm{N}$ and also does not extend much farther east than $185^{\circ} \mathrm{E}$ or west of $160^{\circ} \mathrm{E}$. The averaging of regions in the south 


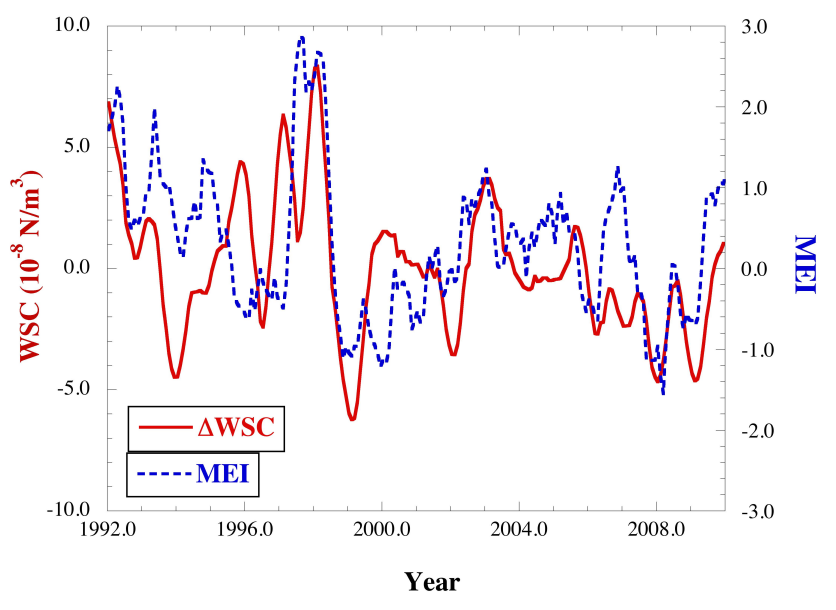

Fig. 3. Time-series of non-seasonal, low-frequency $\Delta \mathrm{WSC}$ (left axis) and MEI (right axis). $\triangle \mathrm{WSC}$ represents the difference in the anomalous WSC north of $35^{\circ} \mathrm{N}$ and anomalous WSC south of $35^{\circ}$ N. See text for details.

without significant ENSO variability may be one explanation for why Song and Zlotnicki observed a correlation that was barely significant. For our analysis, we will utilize a modified WSC index, computed with $<$ WSC_N $>$ averaged over $37^{\circ} \mathrm{N}-42^{\circ} \mathrm{N}, 160^{\circ} \mathrm{E}-185^{\circ} \mathrm{E}$ and $<\mathrm{WSC} \_\mathrm{S}>$ averaged over $28^{\circ} \mathrm{N}-32^{\circ} \mathrm{N}, 160^{\circ} \mathrm{E}-185^{\circ} \mathrm{E}$ (boxes in Fig. 2).

The EOF analysis also allows one to estimate the fraction of variance explained by ENSO in the area, at least the amount of ENSO that is projected onto the first mode. The leading mode explains slightly more than $50 \%$ for both WSC and OBP in the area of $35^{\circ} \mathrm{N}-45^{\circ} \mathrm{N}$ and $160^{\circ} \mathrm{E}-185^{\circ} \mathrm{E}$, where the amplitude of the OBP variation is the largest (indicated by the box in Fig. 2). Thus, although the leading mode does explain about half the low-frequency variance of OBP in the model, it is suggestive that there are additional low-frequency variations uncorrelated with ENSO. This can be observed if we compare our modified WSC index with the MEI (Fig. 3), without performing an EOF analysis. The correlation is 0.51, which, while still significant at the $99 \%$ level, is quite a bit lower than the correlation between MEI and the leading EOF mode. There is a similar drop in the correlation between OBP averaged over the region of $35^{\circ} \mathrm{N}-$ $45^{\circ} \mathrm{N}, 160^{\circ} \mathrm{E}-185^{\circ} \mathrm{E}$ and MEI $(-0.45)$. If the data from 1997 and 1998 are excluded, the correlation drops to 0.39 for WSC and -0.40 for OBP, both of which are barely significant at the $99 \%$ level.

It is clear from an examination of Fig. 3, that while $\Delta$ WSC (Eq. 1) is highly positive during several El Niño events (e.g., 1992, 1997/1998, and 2003), there are also events when it is neither positive, nor large (e.g., 1993, 1995, 2007). From 1992 until 2009, there were 6 El Niño and 6 La Niña events of various intensities as classified by the NOAA Climate Prediction Center (NOAA CPC, 2011). One can better compare the correspondence of $\triangle \mathrm{WSC}$ anomalies and El Niño/La
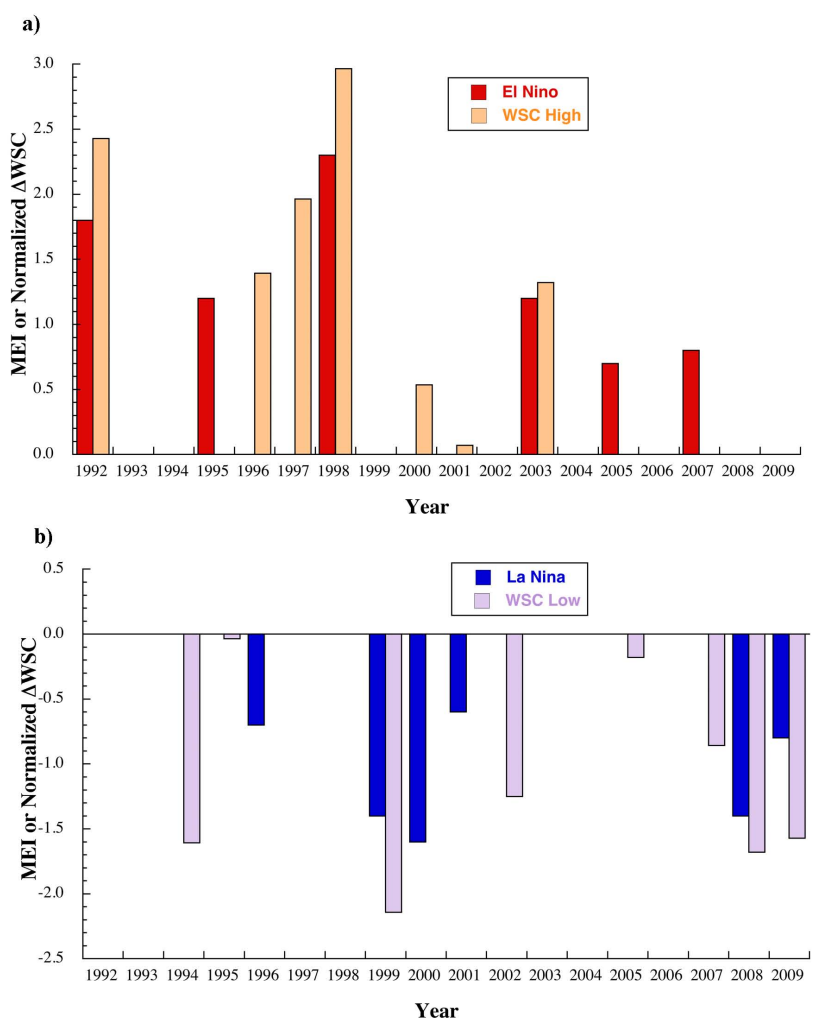

Fig. 4. December-January-February (DJF) averages of (a) MEI during El Niño along with corresponding values of normalized $\Delta$ WSC where $\Delta$ WSC was high and (b) MEI during La Niña events along with corresponding values of normalized $\triangle$ WSC where $\Delta$ WSC was low. Normalized values were computed by dividing by the standard deviation. Also shown are years where the normalized $\Delta \mathrm{WSC}$ exceeded \pm 1 , even if there was no El Niño or La Niña event. Note that the year indicated represents the year for January of the average. Hence, the 1997/1998 El Niño is in 1998.

Niña if the December-January-February (DJF) values of the MEI are plotted for Warm/Cold years, along with the normalized $\triangle$ WSC (Fig. 4). In addition, DJF values of $\Delta$ WSC that exceed \pm 1 standard deviation are also plotted in years without a significant El Niño or La Niña. $\triangle$ WSC was anomalously positive during only half of the El Niño events. All of these exceeded 1 standard deviation, though. $\triangle$ WSC was anomalously positive during DJF for 2 years when there was no El Niño (1995/1996, 1996/1997), although the former year was a weak La Niña. The relationship with La Niña is similar, with $\triangle$ WSC generally being highly negative during the 3 La Niña events of 1998/1999, 2006, and 2008. However, as with the positive values of $\triangle \mathrm{WSC}$, there are several examples where $\triangle \mathrm{WSC}$ is highly negative but there is neither an El Niño or La Niña in the tropics $(1994,2002,2007)$.

Since OBP variations between $35^{\circ} \mathrm{N}-45^{\circ} \mathrm{N}, 160^{\circ} \mathrm{E}-$ $185^{\circ} \mathrm{E}$ are related to the sign and magnitude of $\triangle \mathrm{WSC}$, they will reflect both the ENSO and non-ENSO variability in WSC (Fig. 5). Thus, while the relatively large El Niño/La 


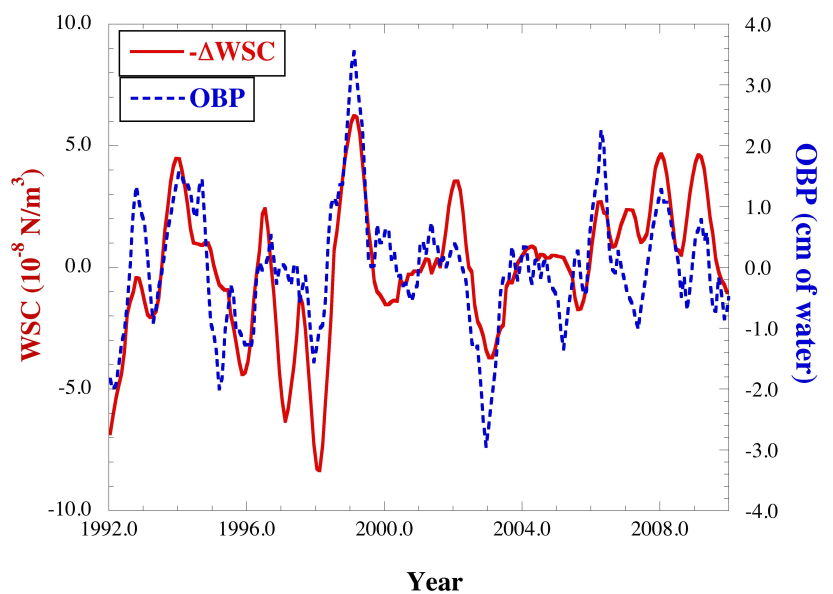

Fig. 5. Time-series of $-\Delta \mathrm{WSC}$ (left axis) and OBP (right axis) from OMCT. The OBP data were averaged over the region $35^{\circ} \mathrm{N}-$ $45^{\circ} \mathrm{N}, 160^{\circ} \mathrm{E}-185^{\circ} \mathrm{E}$ as indicated by the box in Fig. 2. Data were low-pass filtered to isolate non-seasonal, low-frequency variations as described in Sect. 2. The negative value of $\triangle \mathrm{WSC}$ is shown to better see the correspondence since OBP and $\triangle \mathrm{WSC}$ are negatively correlated.

Niña events in the tropical Pacific tend to be associated with large changes in the WSC and OBP in the sub-polar gyre, such as the ones Song and Zlotnicki (2008) discussed for 1982/1983 and 1997/1998, smaller ENSO variations often do not cause a significant change. More importantly, equally large interannual variations in WSC and OBP can occur when no El Niño or La Niña is occurring in the equatorial Pacific. It should not be surprising that there are interannual variations other than ENSO in this area, since the Pacific Decadal Oscillation causes low-frequency changes in the winds over the area (Mantua et al., 1997; Qiu, 2003), and there is evidence of the PDO modulating the amplitude of ENSO events (Yeh and Kirtman, 2005).

Based on the preceding analysis, we can return to the question of whether the long-term increase in OBP observed by Chambers and Willis (2008) is reflective of ENSO variations or of another, unrelated fluctuation. We first extend the comparison of GRACE OBP anomalies to stericcorrected altimetry averaged over the area of $35^{\circ} \mathrm{N}-45^{\circ} \mathrm{N}$, $160^{\circ} \mathrm{E}-185^{\circ} \mathrm{E}$ by 2 more years from the period studied by Chambers and Willis (2008) to show that the trend continues in both data sets at least until the end of 2009 (Fig. 6a). The standard deviation of the monthly differences is $1.5 \mathrm{~cm}$, which is consistent with the uncertainty estimated in the GRACE data by Chambers and Willis (2010) over a region of this size, with a correlation of 0.76 . There is some evidence in the longer record from GRACE that after January 2010, the OBP either leveled out or started to decrease (Fig. 6b). The trend estimated from January 2003 until December 2008 is $0.7 \pm 0.3 \mathrm{~cm} \mathrm{yr}^{-1}$ ( $95 \%$ confidence level) for GRACE, which is nearly identical to the trend estimated
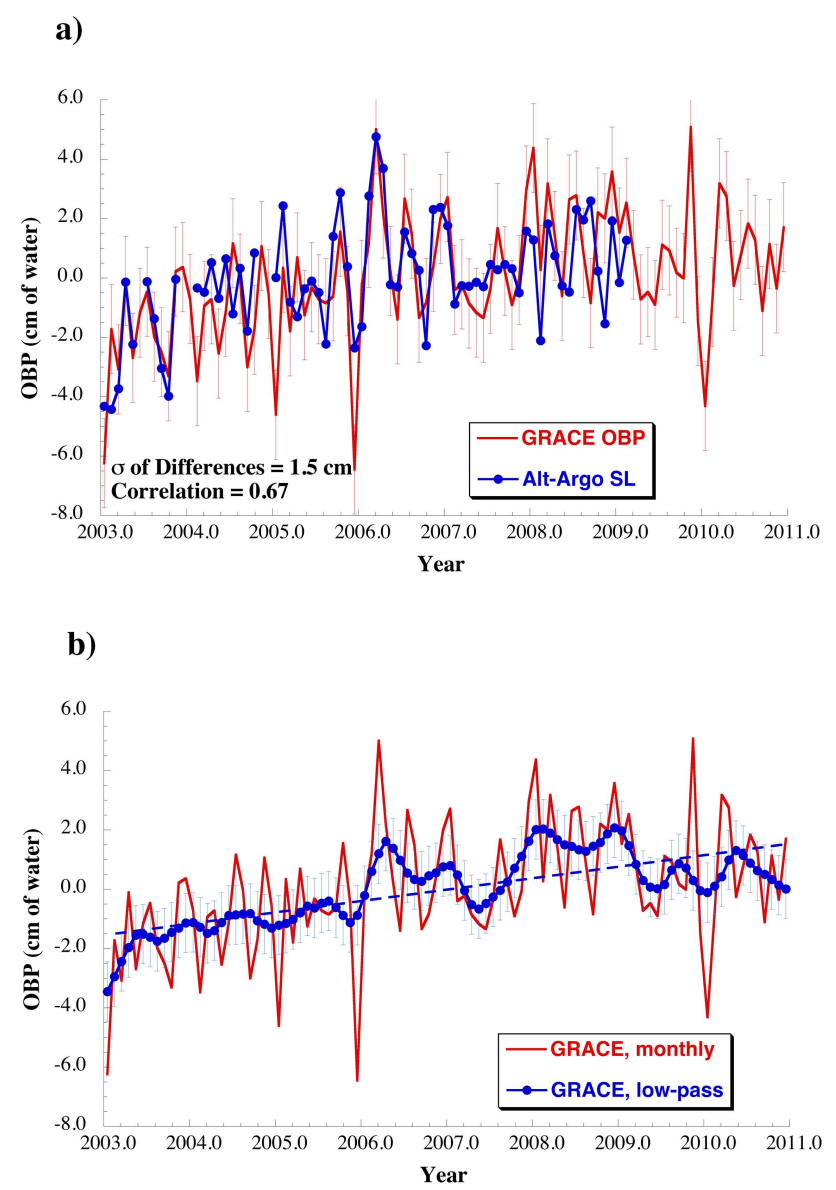

Fig. 6. Monthly, non-seasonal OBP averaged over the region $35^{\circ} \mathrm{N}-45^{\circ} \mathrm{N}, 160^{\circ} \mathrm{E}-185^{\circ} \mathrm{E}$ for (a) GRACE and stericcorrected altimetry (updated from Chambers and Willis, 2008) and (b) GRACE but with an additional low-pass filter as described in text. The dashed line represents the best-fit linear trend.

over the shorter period by Chambers and Willis (2008). The trend in the steric-corrected altimetry is statistically identical $\left(0.5 \pm 0.3 \mathrm{~cm} \mathrm{yr}^{-1}\right)$. The trend estimated to December 2010 in the GRACE data is $0.4 \pm 0.3 \mathrm{~cm} \mathrm{yr}^{-1}$, which is consistent with a downturn in the OBP trend after 2009.

In order to determine whether ENSO variations can account for some of the trend, we fit a parameteric model to the data that includes a bias, linear trend + a parameter that scales the MEI

$y=A_{0}+A_{1}(t-2003.0)+A_{2} \operatorname{MEI}(t)$,

and estimate coefficients $\left(A_{0}, A_{1}, A_{2}\right)$ using linear least squares. When we compare GRACE data with the negative of the MEI (Fig. 7), it appears that the OBP fluctuations are correlated only with the El Niño events of 2003 and 2009, and the La Niña of 2007/2008. Because of this, we have estimated two sets of parameters, the first using all the GRACE observations from January 2003 to December 2010, the second using only observations between January 2003 and July 


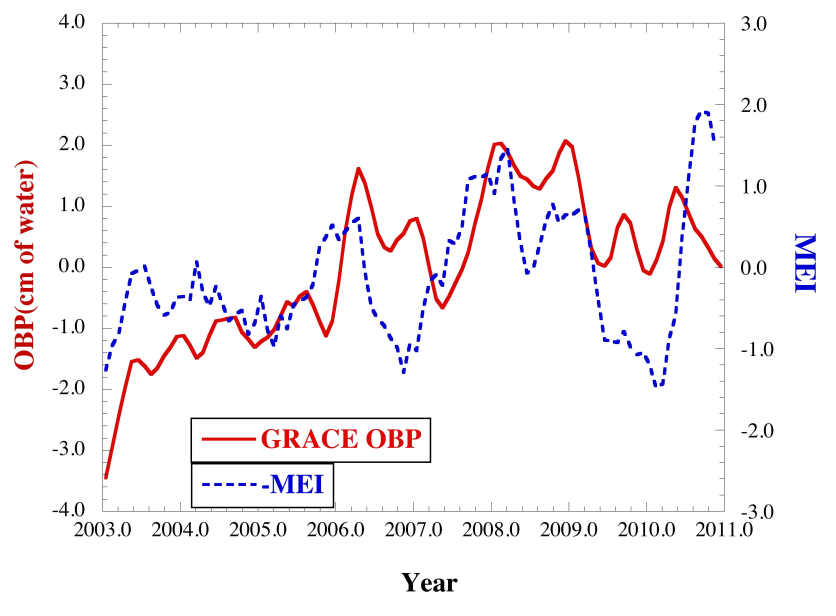

Fig. 7. Time-series of low-pass filtered GRACE OBP from Fig. $6 \mathrm{~b}$ (left axis) and the negative of the MEI (right axis). The negative value of $\triangle \mathrm{WSC}$ is shown to better see the correspondence since $\mathrm{OBP}$ and MEI are negatively correlated.

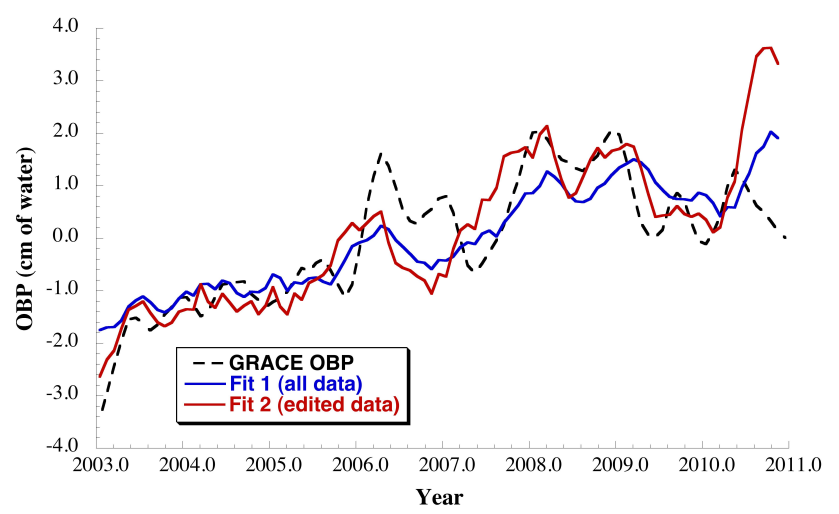

Fig. 8. Time-series of low-pass filtered GRACE OBP as well as two different fits based on parameterizing the ENSO variability. See text (Eq. 2) for a discussion of the model and fits.

2005, as well as March 2007 to December 2010. The fits are shown in Fig. 8. The second fit (based on the reduced data set) clearly fits the observations better in 2003 to 2004, when OBP rises by about $1.5 \mathrm{~cm}$ water equivalent, and in 2007 to 2009 , when it rises by about $3 \mathrm{~cm}$ water equivalent then subsequently falls by $1.5 \mathrm{~cm}$. The fit does not agree with the observed OBP fluctuations in 2006 and 2010, suggesting there are fluctuations unrelated to ENSO.

The more important conclusion of this analysis, however, is that the trend estimated when ENSO variations are parameterized in the fit changes by only $0.04 \mathrm{~cm} \mathrm{yr}^{-1}$, regardless of which fit is used. This means that the ENSO-correlated variations in OBP in the sub-polar gyre do not explain the trend, as Chambers and Willis (2008) originally hypothesized. If $A_{2} \operatorname{MEI}(t)$ based on "Fit 2" is removed from the original data, it is quite apparent that that there is a long-term increase in

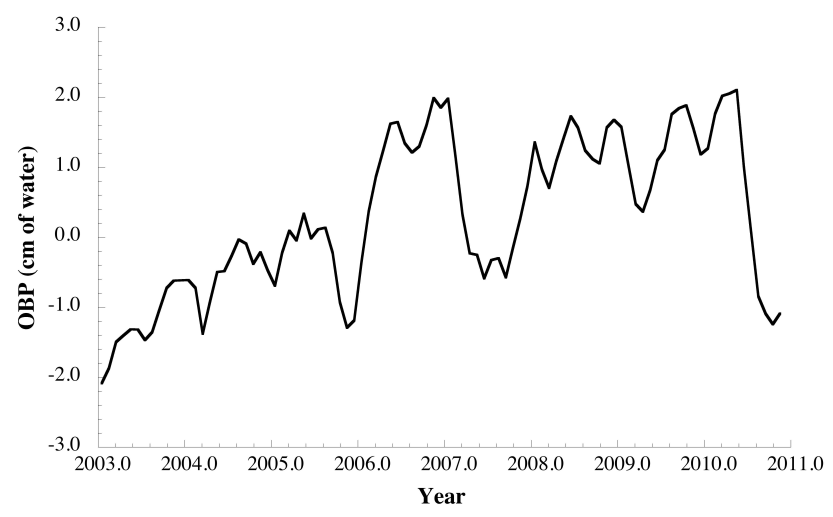

Fig. 9. Residual low-frequency, non-seasonal OBP from GRACE after removing ENSO-correlated variability from Fit 2 in Fig. 8.

OBP until early 2010 in the area unconnected to ENSO. The large drop at the end of the record reflects problems with the fit due to the fact there is a large La Niña event, but no large fluctuation in OBP (Fig. 7).

From an examination of the longer WSC record in the region (Fig. 3), it appears there was a fairly steady multi-year drop in $\triangle$ WSC over the same period that is unprecedented in the record back to 1992 . This can be more clearly seen if the data are low-pass filtered with a 2-year Gaussian to reduce the ENSO-variability (Fig. 10). The drop in $\triangle \mathrm{WSC}$ begins in early 2004 and lasts longer and has a greater change than any of the previous fluctuations (e.g., 1997-2000). The OBP output from OMCT shows similar anti-correlated lowfrequency oscillations up to roughly 2005 , but at that point shows no significant change for the next 4 years, unlike what is observed by GRACE, steric-corrected altimetry, and satellite WSC in the region.

OMCT is forced by ECMWF winds, not the satellite observed winds. Although the satellite winds are assimilated into ECMWF, other observations are as well, which may bias the model away from the satellite observations. When we compare $\triangle$ WSC computed from ECMWF winds (only available to us for 2003 to 2008), we find that the ECMWF winds are significantly biased relative to the satellite winds starting in 2005-2006, leading to a much smaller trend in $\Delta \mathrm{WSC}$. In fact, the trend in $\triangle \mathrm{WSC}$ based on the satellite winds is 2.5 times larger than that computed from the ECMWF model winds over the period from 2003 until the end of 2008. Since both GRACE and steric-corrected altimetry observe OBP changes over this period that are consistent with the trend in the satellite-derived wind stress curl, this suggests a significant error in the ECMWF winds in this region over this time period. 


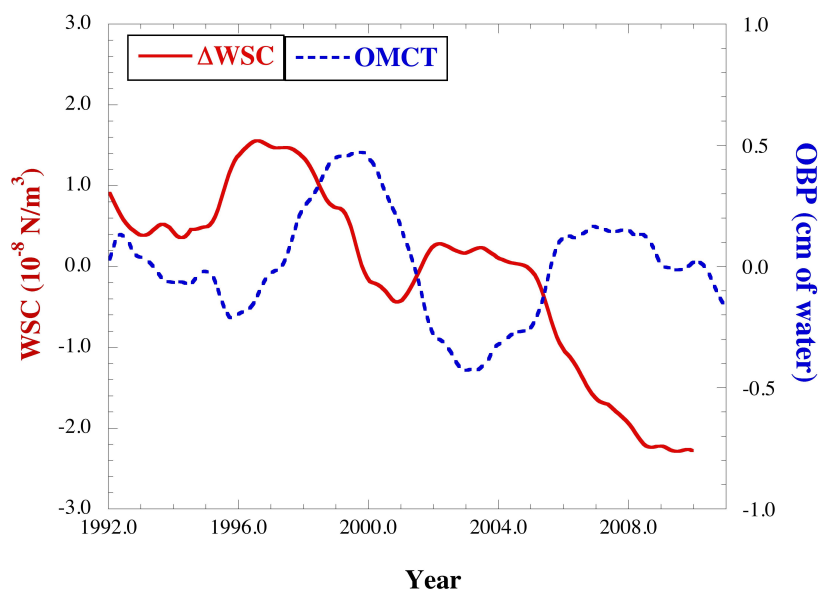

Fig. 10. $\triangle$ WSC (solid line, left axis) and OBP (dashed line, right axis) after low-pass filtering with a 2-year Gaussian to reduce ENSO and other interannual variability.

\section{Conclusions}

After analyzing a long time-series of wind-stress curl from satellite observations, ocean bottom pressure from a model and GRACE, we conclude that while there is significant interannual variability in wind-stress curl that drives OBP variations in the sub-polar gyre, only part of it is related to ENSO in the tropical Pacific, as previously pointed out by Song and Zlotnicki (2008). During large El Niño events (like the one in 1997/1998), the wind-stress curl is anomalously positive north of $35^{\circ} \mathrm{N}$ and anomalously negative south of $35^{\circ} \mathrm{N}$, which causes a transport of mass away from the subpolar gyre into the sub-tropical gyre, leading to a significant decrease in OBP in the area between $35^{\circ} \mathrm{N}$ to $45^{\circ} \mathrm{N}$ and $150^{\circ} \mathrm{E}-190^{\circ} \mathrm{E}$. During large La Niña events, the wind curl changes lead to a transport of mass back into the sub-polar gyre that is reflected by an increase in the OBP. This mode is quite similar to the seasonal mode, albeit with a different frequency. Thus, the difference in $\mathrm{WSC}$ across $35^{\circ} \mathrm{N}$ is positively correlated with ENSO indices, while OBP is negatively correlated. These results generally confirm the previous analysis of Song and Zlotnicki (2008).

This work has further quantified the relationship, however. The ENSO-correlated variations explain roughly $50 \%$ of the variance in either WSC or OBP in the region. The amplitude of OBP variability correlated with ENSO in the region is of order $\pm 1 \mathrm{~cm}$ of equivalent SL, but can sometimes reach $3 \mathrm{~cm}$ for large events, such as the 1998/1999 La Niña (Fig. 5). In addition to the ENSO-variations, however, there are other interannual variations in WSC in the region that sometimes cause large anomalous OBP changes unconnected to ENSO. This accounts for the lower correlations of OBP and WSC with ENSO indices than between OBP and WSC. Further work is necessary to understand the mechanisms and patterns of these interannual fluctuations in WSC in the North Pacific.

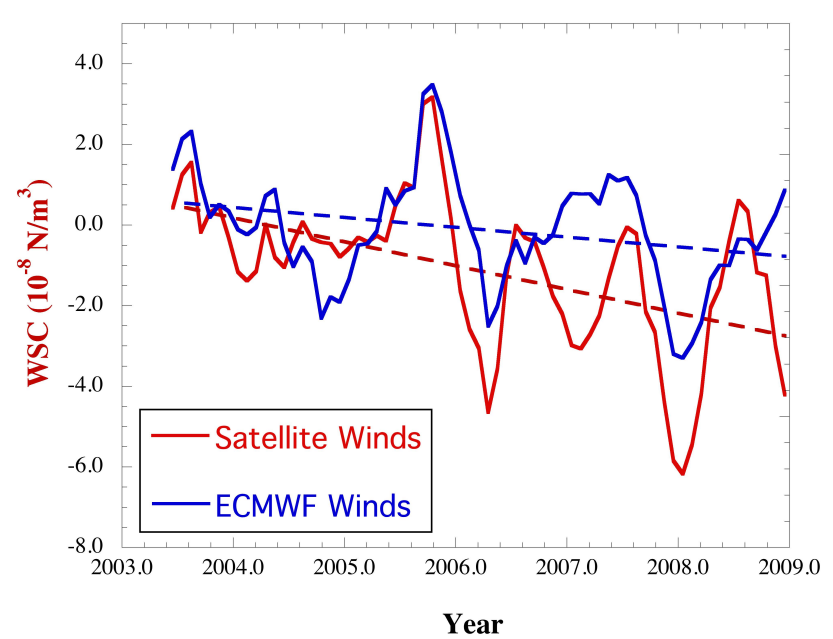

Fig. 11. $\triangle W S C$ computed from satellite winds and ECMWF winds. The dashed lines indicate the best-fit linear trend from mid2003 until late-2008.

While the ENSO and other interannual fluctuations are significant, they cannot explain the low-frequency trend in GRACE OBP that was observed by Chambers and Willis (2008) and which has lasted until at least early 2009 (Fig. 6b). Although some of this trend may be related to residual aliasing from errors in the tide models used in GRACE processing, recent studies based on estimating tides directly from GRACE models suggest that the tidal constituent with the longest alias ( $\mathrm{K}_{1}, 7.46$ years) has a error of at most $1 \mathrm{~cm}$ amplitude in the region (Han et al., 2007; their Fig. 11). Over the shorter record used by Chambers and Willis (2008), such a tide error could potentially cause an apparent trend of $\sim 0.3 \mathrm{~cm} \mathrm{yr}^{-1}$. However, over the longer 8 -year record examined here, a $\mathrm{K}_{1}$ alias would see a complete oscillation and cause no trend. Furthermore, the stericcorrected altimetry data have been extended past 2007 to the end of 2008 (Fig. 6a) and they also indicate a continuing trend. Note that the $K_{1}$ alias period for altimetry is much smaller than 1-year, so will not contribute to a potential trend in the altimeter data as in GRACE. Thus, because two independent data (GRACE and steric-corrected altimetry) indicate a long-term trend between 2003 and at least 2009, we have to conclude it is real.

Our analysis indicates such low-frequency variations have occurred previously in WSC and OBP (Fig. 10), but that the length of time for a complete oscillation between 1992 and 2003 was of order 4 to 5 years. The exact mechanism for these wind variations is not known precisely, although they are most likely related to the Pacific Decadal Oscillation, which is known to cause large, interannual fluctuations in the winds in the area (Mantua et al., 1997; Qiu, 2003), as well as modulate the power of ENSO amplitudes in other regions of the Pacific (Yeh and Kirtman, 2005). 
Although the OBP output from OMCT does not see the same long-term trend as GRACE in the region starting in 2003, we find that there is a significant difference in the WSC computed from satellite winds starting in 2005-2006 with those computed from ECMWF that were used to force OMCT. The trend in $\triangle \mathrm{WSC}$ for the satellite winds is 2.5 times greater than that for the ECMWF wind data from 2003 until 2008. Moreover, the change in the satellite WSC is anomalously large compared to the previous decade and longer-lasting with a relatively steady trend over $6+$ years. The change in winds is consistent with a flux of mass into the sub-polar gyre, which would cause a positive trend in OBP. Whether this alone explains the difference between the model and GRACE observations still needs to be tested by running a model with winds more consistent with the satellite observations after 2006. This is beyond the scope of this current paper, but will be a point for future investigation.

Acknowledgements. We appreciate J. Willis for sharing his calibrated and validated Argo data with us. The GRACE data were analyzed with support by the NASA Earth Science REASoN and "Making Earth System Data Records for Use in Research Environments" (MEASURES) Programs, and are available at http://grace.jpl.nasa.gov. The OMCT output is furnished by the GRACE Science Data System and is available at the NASA Physical Oceanography Distributed Active Archive Center (PO.DAAC) at Jet Propulsion Laboratory, Pasadena, CA. The wind data are from the Cross-Calibrated Multi-Platform (CCMP) Ocean Surface Wind Components Project at the PO.DAAC (http://podaac.jpl.nasa.gov/DATA\{_\}CATALOG/ccmpinfo.html). This research was carried out under Grant NNX08AF01GX from the NASA GRACE Science Team.

Edited by: J. Schröter

\section{References}

Atlas, R., Hoffman, R. N., Bloom, S. C., Jusem, J. C., and Ardizzone, J.: A multiyear global surface wind velocity data set using SSM/I wind observations, Bull. Amer. Meteor. Soc., 77, 869882, 1996.

Bingham, R. J., Hughes, C. W.: Observing seasonal bottom pressure variability in the North Pacific with GRACE, Geophys. Res. Lett., 33, L08607, doi:10.1029/2005GL025489, 2005.

Chambers, D. P.: Evaluation of new GRACE time-variable gravity data over the ocean, Geophys. Res. Lett, 33, L17603, doi:10.1029/2006GL027296, 2006.

Chambers, D. P. and Willis, J. K.: Analysis of large-scale ocean bottom pressure variability in the North Pacific, J. Geophys. Res., 113, C11003, doi:10.1029/2008JC004930, 2008.
Chambers, D. P. and Willis, J. K.: A Global Evaluation of Ocean Bottom Pressure from GRACE, OMCT, and StericCorrected Altimetry, J. Atmos. Ocean. Tech., 27, 1395-1402, doi:10.1175/2010JTECHO738.1, 2010.

Flechtner, F.: AOD1B Product Description Document for Product Releases 01 to 04, GRACE 327-750, CSR publ. GR-GFZ-AOD0001 Rev. 3.1, University of Texas at Austin, 43 pp., 2007.

Fu, L.-L. and Qiu, B.: Low-frequency variability of the North Pacific Ocean: The roles of boundary- and winddriven baroclinic Rossby waves, J. Geophys. Res., 107, 3220, doi:10.1029/2001JC001131, 2002.

Han, S.-C., Ray, R., and Luthcke, S.: One centimeter level observations of diurnal ocean tides from global monthly mean time-variable gravity fields, J. Geodesy, 84, 715-729, doi:10.1029/2007GL031540, 2007.

Large, W. G. and Pond, S.: Sensible and latent heat flux measurements over the ocean, J. Phys. Oceanog., 12, 464-482, 1982.

Mantua, N. J., Hare, S. R., Zhang, Y., Wallace, J. M., and Francis, R. C.: A Pacific interdecadal climate oscillation with impacts on salmon production, Bull. Am. Met. Soc., 78, 1069-1079, 1997.

Miller, A. J., Cayan, D. S., and White W. B.: A westward-intensified decadal change in the North Pacific thermocline and gyre-scale circulation, J. Climate, 11, 3112-3127, 1998.

NOAA CPC, Cold and warm episodes by season, http: //www.cpc.ncep.noaa.gov/products/analysis_monitoring/ ensostuff/ensoyears.shtml, last accessed: 17 May 2011.

Ponte, R.: A preliminary model study of the large-scale seasonal cycle in bottom pressure over the global ocean, J. Geophys. Res., 104, 1289-1300, 1999.

Qiu, B.: Large-scale variability in the midlatitude subtropical and subpolar North Pacific Ocean: Observations and causes, J. Phys. Ocean., 32, 352-375, 2002.

Qiu, B.: Kuroshio extension variability and forcing of the Pacific Decadal Oscillations: Responses and potential feedback, J. Phys. Ocean., 33, 2465-2482, 2003.

Qiu, B. and Joyce, T. M.: Interannual variability in the mid- and low-latitude western North Pacific, J. Phys. Oceanogr., 22, 10621079, 1992.

Song, Y. T. and Zlotnicki, V.: Subpolar ocean-bottom-pressure oscillation and its links to the tropical ENSO, Int. J. Remote Sensing, 29, 6091-6107, doi:10.1080/01431160802175538, 2008.

Thomas, M.: Ocean induced variations of Earth's rotation - Results from a simultaneous model of global ocean circulation and tides, Ph. D. diss., 129 pp., Univ. of Hamburg, Germany, 2002.

Yeh, S.-W. and Kirtman, B. P.: Pacific decadal variability and decadal ENSO amplitude modulation, Geophys. Res. Lett., 32, L05703, doi:10.1029/2004GL021731, 2005.

Wolter, K. and Timlin, M. S.: Measuring the strength of ENSO events - how does 1997/1998 rank? Weather, 53, 315-324, 1998. 